\title{
Physicochemical and Biomechanical Stimuli in Cell-Based Articular Cartilage Repair
}

\author{
Holger Jahr • Csaba Matta • Ali Mobasheri
}

Published online: 2 April 2015

(C) The Author(s) 2015. This article is published with open access at Springerlink.com

\begin{abstract}
Articular cartilage is a unique load-bearing connective tissue with a low intrinsic capacity for repair and regeneration. Its avascularity makes it relatively hypoxic and its unique extracellular matrix is enriched with cations, which increases the interstitial fluid osmolarity. Several physicochemical and biomechanical stimuli are reported to influence chondrocyte metabolism and may be utilized for regenerative medical approaches. In this review article, we summarize the most relevant stimuli and describe how ion channels may contribute to cartilage homeostasis, with special emphasis on intracellular signaling pathways. We specifically focus on the role of calcium signaling as an essential mechanotransduction component and highlight the role of phosphatase signaling in this context.
\end{abstract}

Keywords Articularcartilage $\cdot$ Cartilage repair · Regenerative medicine $\cdot$ Autologous chondrocyte implantation . Chondrocyte metabolism · Functional tissue engineering .

This article is part of the Topical Collection on Osteoarthritis

\section{H. Jahr}

Department of Orthopaedic Surgery, University Hospital RWTH

Aachen University, Pauwelsstraße 30, 52074 Aachen, Germany

H. Jahr $\cdot$ C. Matta $\cdot$ A. Mobasheri $(\square)$

The D-BOARD European Consortium for Biomarker Discovery, Surrey, UK

e-mail: a.mobasheri@surrey.ac.uk

\section{A. Mobasheri}

e-mail: ali.mobasheri.manuscripts@gmail.com

URL: http://www.d-board.eu/dboard/index.aspx

\section{Matta $\cdot$ A. Mobasheri}

Department of Veterinary Preclinical Sciences, School of Veterinary

Medicine, Faculty of Health and Medical Sciences, University of

Surrey, Duke of Kent Building, Guildford, Surrey GU2 7XH, UK
Cartilage bioengineering $\cdot$ Mesenchymal stem cell . Intracellular signaling pathways

$\begin{array}{ll}\text { Abbreviations } \\ \text { ACI } & \text { Autologous chondrocyte implantation } \\ \text { ALP } & \text { Alkaline phosphatase } \\ \text { CCI } & \text { Characterized chondrocyte implantation } \\ \text { Cn } & \text { Calcineurin } \\ \text { CREB } & \text { cAMP response element binding protein } \\ \text { CsA } & \text { Cyclosporine A } \\ \text { ECM } & \text { Extracellular matrix } \\ \text { ERK } & \text { Extracellular signal-regulated kinase } \\ \text { FAK } & \text { Focal adhesion kinase } \\ \text { FCD } & \text { Fixed charge density } \\ \text { FTE } & \text { Functional tissue engineering } \\ \text { GAG } & \text { Glycosaminoglycan } \\ \text { HP } & \text { Hydrostatic pressure } \\ \text { MAPK } & \text { Mitogen-activated protein kinase }\end{array}$

C. Matta

Department of Anatomy, Histology and Embryology, Faculty of Medicine, University of Debrecen, Nagyerdei krt. 98,

Debrecen 4032, Hungary

A. Mobasheri

Arthritis Research UK Centre for Sport, Exercise and Osteoarthritis, Arthritis Research UK Pain Centre, Medical Research Council and Arthritis Research UK Centre for Musculoskeletal Ageing Research, University of Nottingham, Queen's Medical Centre,

Nottingham NG7 2UH, UK

A. Mobasheri

Center of Excellence in Genomic Medicine Research (CEGMR),

King Fahd Medical Research Center (KFMRC), King AbdulAziz

University, Jeddah 21589, Kingdom of Saudi Arabia 


$\begin{array}{ll}\text { MSC } & \text { Mesenchymal stem cell } \\ \text { NFAT } & \text { Nuclear factor of activated T lymphocytes } \\ \text { OA } & \text { Osteoarthritis } \\ \text { OP } & \text { Osmotic pressure } \\ \text { PEMF } & \text { Pulsed electromagnetic field } \\ \text { PG } & \text { Proteoglycan } \\ \text { PKA } & \text { Protein kinase A } \\ \text { PKC } & \text { Protein kinase C } \\ \text { RVD } & \text { Regulatory volume decrease } \\ \text { TRPV } & \text { Transient receptor potential vanilloid channel } \\ \text { FF } & \text { Fluid flow }\end{array}$

\section{Introduction}

The unique biomechanical properties of articular cartilage are attributed to the structure, composition, and organization of its extracellular matrix (ECM) macromolecules. The cartilage ECM is mainly composed of a collagen fiber network (type II collagen with type IX and XI) and large aggregating proteoglycans (PGs) entrapped within. The fixed negative charges on the glycosaminoglycan (GAG) side chains of PGs attract counteracting ions, which drive the movement of large amounts of osmotically obliged water into the matrix [1]. The high osmotic milieu and the tissue swelling maintain the hydrostatic pressure and viscoelastic properties of cartilage. The highly sulfated GAG side chains of PGs, through attracting mobile cations, are responsible for the characteristically high negative fixed-charge density (FCD) [2]. Intertwined collagens and PGs combine to create the tissue rigidity by entrapping solutes and water, giving cartilage its unique biomechanical properties, to withstand large compressive and shear forces without failing [3]. Articular cartilage absorbs stresses generated during joint loading and contributes to joint lubrication [1,4]. An intact collagen network restricts swelling and, in combination with sulfated GAGs, determines the osmotic pressure (OP) of the extracellular fluid around chondrocytes, which ranges from 350 to $480 \mathrm{mOsm}$ in healthy cartilage [5].

The electrochemical properties of articular cartilage arise from the flow of "free" electrolytes (e.g., $\mathrm{Na}^{+}, \mathrm{K}^{+}, \mathrm{Ca}^{2+}$ ) passing the relatively "fixed" $\mathrm{FCD}$ (e.g., $\mathrm{SO}_{4}{ }^{2-}$ ) distributed along the PGs [6] resulting in electrokinetic phenomena and chargedependent osmotic swelling pressures (i.e., Donnan osmotic pressure) [7-9]. The FCD permits tissue hydration, charged species transport, and other electrochemical responses [10]. Mow et al. postulated that the ECM is a mechanical signal transducer, receiving loading as input to generate an output of multiple biophysical signals [11].

Interestingly, reports on physiologically relevant values of tensile or shear forces in natural cartilage or in tissueengineered constructs are sparse [12], as is the knowledge about the molecular identity of the sensory components and signaling apparatus that convert various environmental forces (e.g., deformation, shear stress and fluid flow, hydrostatic pressure (HP), and extracellular ionic milieu (i.e., OP) as well as magnetic and electric forces), into cellular responses. We provide a brief overview of how these forces might be exploited to facilitate cartilage regeneration, with special emphasis on intracellular signaling, which is often understudied in the context of cartilage bioengineering.

\section{Cartilage Pathologies}

Traumatic local damage [13-15], usually in younger patients, and whole joint erosion, as in osteoarthritis (OA) [16] in the elderly, are challenging areas of regenerative orthopedics [17]. To date, there is no successful targeted therapy that would halt or even reverse OA progression; current management including inflammatory medications, total joint replacements, or analgesics only allow palliative treatment [18 $]$. There is a pressing need for targeted treatment options, ideally at the early, asymptomatic stages of the disease. The earliest signs of articular cartilage degeneration during OA are net depletion of PGs [10, 19-21], subsequent loss of the collagen network [22], and diminished intrinsic compressive stiffness, affecting chondrocyte deformation, metabolic activities, and electromechanical events within cartilage under body load [10,23]. Severity-dependent catabolic events during the course of OA reduce extracellular osmolarity, resulting in reduced viscoelastic tissue properties, corresponding biomechanical inferiority $[5,24]$, and eventually increased deformation of cartilage under mechanical load. Elevated levels of inflammatory mediators that promote matrix degradation may also accompany these changes.

\section{Regenerative Approaches}

Autologous chondrocyte implantation (ACI) [25] surpasses existing procedures for treating focal defects, but is unable to fully restore functional hyaline cartilage ad integrum. A potentially better procedure for structurally repairing symptomatic cartilage defects in the knee is characterized chondrocyte implantation (CCI) which has a more favorable outcome compared to microfracturing [26].

A major challenge is the complex zonal structure of cartilage tissue, which is important for its load-bearing properties [27-29]. The sparse available data indicate that mechanical properties significantly vary between articular cartilage zones [30-32]. The lack of mechanical homogeneity may be important for mechanosensation, signal transduction, and chondrocyte phenotypic stability.

Another major challenge of present tissue engineering strategies for cartilage repair is the limited integration of the 
constructs into the surrounding host tissue [33], often resulting in local cell death at the defect margins [34]. The goal, therefore, is to create tissue functionality prior to implantation by enhancing the rate and quality of tissue growth through creating in vivo-like conditions in vitro. Various environmental stimuli for promoting cartilage regeneration are discussed in the following sections.

\section{Stimulating Functional Cartilage Tissue Engineering}

\section{Electrical Stimulation}

Mechanoelectrical transduction phenomena occurring naturally within the cartilage due to the FCD have prompted the development of experimental electrical stimulation protocols for therapeutic cartilage repair $[35,36]$. Therapeutic devices involving electrical stimulation are increasingly entering the clinical market [37], despite rather discouraging early results $[38,39]$. More recently, Brighton et al. observed anabolic effects [40] that may hold potential to treat osteoarthritic lesions [18•]. Our current appreciation of underlying molecular mechanisms, however, is rudimentary.

\section{Magnetic Stimulation}

Since its FDA approval in 1979, pulsed electromagnetic field (PEMF) therapy has been widely used in orthopedics to treat poorly healing fractures [41, 42•]. Although the biology of how PEMF stimulates bone formation is only partially understood [43] and may originate from stimulating progenitor cell differentiation [44], its clinical use has provided a rationale for applying (P)EMF in musculoskeletal tissue engineering [45, 46].

Data from randomized controlled trials now suggest that PEMF improves clinical scores and function even in patients with knee OA [47]. While (low-frequency) PEMF therapy barely influences the biosynthetic activity of human OA chondrocytes in vitro [48], it increases PG release in alginate culture [49]. PEMF increases anti-inflammatory effects in the human costal chondrocyte cell line T/C-28a2 [50], and, like IGF-1, it augments chondroprotective anabolic activities such as PG synthesis in human OA cartilage explants, possibly by counteracting the effects of IL-1 $\beta$ in early stages of OA [51]. A study in ovariectomized rats, aiming at simulating postmenopausal osteoarthritis, reported an interesting systemic effect of PEMF therapy on estrogen metabolism that reduced apoptosis and matrix metalloproteinase (MMP)13 expression in knee joint cartilage [52]. However, since current evidence for PEMF as a diseasemodifying OA therapy is still weak, further studies are needed to elucidate its molecular basis.

\section{Mechanical Stimulation}

In comparison to the rather limited evidence for effects of magnetic and electrical stimulation, a vast body of studies have described the consequences of mechanical stimulation on articular cartilage or chondrocytes in tissue engineering strategies [18•]. We review mainly cellular responses of chondrocytes and aspects closely related to osmotic stress, such as compressioninduced changes in HP and OP, as both are essential for stimulating chondrocyte physiology and useful for manipulating chondrocyte metabolism and phenotype [53].

Mechanical stimulation is an important regulator of chondrocyte metabolism that is required for maintaining normal cartilage matrix properties $[54,55]$ and a well-established cue for improving mechanical properties of tissueengineered cartilage [27], as reviewed by Vunjak-Novakovic et al. [56] and Lee et al. [57]. A plethora of bioreactors have been developed in which mechanical forces are applied via compression, HP, shear, multimodal compression and shear, vibration, bi-axial tension, and friction [18•]. While static loading of tissue-engineered cartilage constructs, in general, results in suppression of ECM biosynthesis, intermittent dynamic loading is usually beneficial and increases the biosynthetic activity of chondrocytes. The cellular response to mechanical stimuli always depends on magnitude, frequency, and duration of the stimulus, as well the relative timing of the loading, the culture period, and the subpopulation of chondrocytes. Importantly, the balanced activities of catabolic and anabolic factors may be needed to stimulate native-like ECM synthesis [58, 59].

Intrinsic Mechanical Stimulation and Substrate Properties Cyclic compression is required for chondrogenesis [60], while its impact on the intrinsic material properties of cartilage is an underappreciated aspect in tissue engineering. Using surface topography, stiffness, or patterns to induce mesenchymal stem cell (MSC) proliferation or differentiation [61] holds a lot of potential for enhancing musculoskeletal regeneration [62•].

Our understanding of how cells sense the stiffness of ECM or biomimetic substrates is rudimentary. Emerging mechanisms of biophysically induced signals include focal adhesions and cytoskeletal or Rho GTPase functions $[63,64]$. Local matrix stiffness can determine cell development, differentiation, and regeneration through adhesion complexes [64] with the actin-myosin cytoskeleton generating intrinsic contractile forces by "sensing" substrate properties via prestretching through actin stress fibers; linking integrin transmembrane receptors to ECM in mechanosensation enables primary cells to alter their function in response to exogenous forces [65] or oxygen tension and local cell density [66]. Initial attempts suggest the feasibility of creating 3D stiffness gradients in hydrogels [67] to re-differentiate chondrocytes. By manipulating substrate elasticity and adhesion density 
[68], stiffness may affect proliferation and RGD adhesion site density during cellular differentiation. While the banding periodicity of collagen fibers in the ECM is $67 \mathrm{~nm}$ [69] and the RGD epitopes of fibronectin fibers are $\geq 73 \mathrm{~nm}[70,71]$, cells are clearly sensitive to changes in interparticle spacing of about $1 \mathrm{~nm}$ over a cell length [63],

That MSC fate can be re-directed, even after weeks, by switching the biophysical microenvironment [72••] holds promises for several cartilage-related tissue engineering applications. In contrast to generally unfavorable static compression, static pre-stretching of biomaterials may beneficially alter (stem) cell behavior [73] through regulation of epigenetic events [74]. A meshwork of intermediate filaments and lamins physically links chromatin to the cytoskeleton-mediated extracellular signal reception $[75,76]$. Mechanical forces arising from matrix rigidity and nanotopography can physically affect the structural organization of the nucleus [77], possibly directly altering gene expression and mechanical properties [63].

In combination with mechanical stimulation, incorporation of chemical groups such as sulfates may improve chondrocyte proliferation while inhibiting hypertrophic differentiation [78, 79]. By using intrinsic biomaterial cues to stimulate migration, cell-seeded scaffolds appear promising for cartilage repair. Similar to MSCs, chondrocytes respond to HP, fluid flow (FF) and the accompanying shear stress, substrate strain and stiffness or topography, and electromagnetic fields [80]. Fully synthetic hydrogels can provide independent control over physical and adhesive properties [81] for use in cartilage regenerative medicine [82].

\section{Osmotic Stimulation}

Chondrocytes in cartilage represent cells under pressures of different natures, like deformation, hydrostatic pressure, extracellular ion composition (i.e., OP), and streaming potential (i.e., FF) [54]. Further, the concept is generally accepted that matrix turnover by chondrocytes is influenced by changes to the intracellular composition (e.g., cell volume, $\mathrm{pH}$, and ionic content). The pericellular microenvironment functions in situ to mediate the chondrocyte (or chondron) responses to physicochemical changes associated with joint loading [83]. During compression-induced changes in OP, the pericellular matrix exerts important functions through amplifying cell volume changes [84]; such findings argue in favor of using chondrons, rather than isolated chondrocytes, for osmoinduced cartilage tissue engineering.

About 15 years ago [11], Mow et al. described the sometimes counter-intuitive effects of flow-induced compression of the ECM and hypothesized that this friction-drag effect is likely of major importance for fluid flow through the ECM. Changes in HP and OP are essential for chondrocyte physiology and useful for manipulating their metabolic function and phenotype [53]. Applying controlled HP to cartilage or chondrocytes can be technically challenging [53], while OP is robustly defined as chemical. Unlike OP, tonicity is influenced only by solutes that cannot cross the cell membrane. Although chemical loading (i.e., OP) and mechanical loading (i.e., HP) may not be exactly equivalent [85], the combination of HP and OP produce gene expression profiles different from those with OP alone, each stimulus by itself often results in similar effects such as the stimulation of sulfated GAG synthesis [53].

As OP is a state quantity, it changes during compressive joint loading and off-loading; with zone-dependent concentrations of sulfated GAGs causing OP gradients in articular cartilage [86]. In each zone, chondrocytes are subject to different HPs and OPs due to weight bearing and joint loading [53, 32]. Applying HPs from 0 to $0.5 \mathrm{MPa}$ at $0.5 \mathrm{~Hz}$ and OPs from 300 to $450 \mathrm{mOsm}$ can upregulate anabolic and catabolic molecules in all three major zones in a descending order of magnitude from the surface to the deep zone. Interestingly, HP offloading maintains anabolic messenger RNAs (mRNAs) and reduces catabolic mRNAs, while high OP retains mainly catabolic mRNAs [53]. Superficial zone-derived cells are most sensitive to changes in HP or OP [53], which may explain discrepancies between chondrocytes isolated from "normal" and OA cartilage. The effects of OP on viscoelastic and physical properties of chondrocytes are well described [87]. Tonicity enhancer binding protein (TonEBP, also known as nuclear factor of activated $\mathrm{T}$ cells (NFAT)5) stimulates multiple cellular pathways for adaptation to osmotic stress [88, 89] and organic osmolyte-dependent and independent pathways [90]. Physiological and pathophysiological stimuli such as cytokines, growth factors, receptor and integrin activation, contractile agonists, ions, and reactive oxygen species have been implicated in the positive regulation of TonEBP expression and activity in diverse cell types [91].

Under standard FCS-containing expansion culture conditions, proliferation of human chondrocytes seems to be unhampered up to physiological osmolarity levels (i.e., 350-400 mOsm) [92, 93]. Proteomic analysis of serum-free expanded chondrocytes has confirmed a cutoff threshold of about 350 mOsm, above which cell cycle progression and proliferation appears compromised [94, 95].

Molecular Aspects The response to osmotic loading seems to depend on the nature of the osmotic stimulation and the chondrocyte phenotype, which is related to passage number and pathological state [96]. Osmotic loading differentially regulates SOX9 and COL2A1 mRNA stability posttranscriptionally [97]. In nucleus pulposus cells, NFAT5 [98], together with intracellular $\mathrm{Ca}^{2+}$ [99] and MEK/extracellular signal-regulated kinase (ERK) signaling [100], control cell function, survival, and sulfated GAG synthesis [101, 102]. Hyperosmotic stress induces 
volume changes and $\mathrm{Ca}^{2+}$ transients in chondrocytes by transmembrane ion channels, phospholipids, and G-protein coupled pathways [103].

Pritchard et al. [104] found that IL-1 $\alpha$ alters the normal volumetric and $\mathrm{Ca}^{2+}$ signaling response of porcine chondrocytes to OP through mechanisms involving F-actin remodeling and Rho GTPases. Human OA chondrocytes have a more positive membrane potential (i.e., $-26 \pm 4 \mathrm{mV}$ ) than healthy cells and show reduced $\left[\mathrm{Ca}^{2+}\right]_{\mathrm{o}}$ independent protein kinase $\mathrm{C}$ (PKC) $\alpha$-mediated hyperpolarization upon hyperosmotic stimulation [105].

Osmotic loading is known to modulate chondrocyte height, width, and volume in situ, and OP may modulate cell shape in accordance with the primary collagen fibril direction [106], as well as altering nuclear size and shape [107]. Interestingly, osmotic sensitivity of nuclear shape and volume appeared to be independent of the actin cytoskeleton. While compression (and thus increased OP) reduces the ECM, cellular, nuclear, rER, and mitochondrial volumes, the Golgi apparatus seems relatively resistant to intraorganelle water loss [108]. This may, at least partially, explain some of the observed posttranscriptional effects of OP [97].

Clinical Relevance Chondrocyte shrinkage by raised hyperosmotic pressure $(\geq 480 \mathrm{mOsm})$ may protect cells. While most cell-based chondral repair strategies aim at re-differentiation of routinely expanded, dedifferentiated chondrocytes, van der Windt et al. showed that dedifferentiation can be delayed by harvesting and expanding cells under elevated (i.e., physiological, $380 \mathrm{mOsm}$ ) osmolarity [92]. Interestingly, combining physiological osmolarity with inhibition of calcineurin activity can increase the expression of anabolic genes and suppress catabolic genes, as well as hypertrophic markers, in human OA and "normal" chondrocytes [93] and may be a promising strategy for improving cell-based chondral defect repair. The clinical potential of applying osmolarity to improve the chondrocyte phenotype is hard to predict from present in vitro data, given the depth zone dependence of osmotic responses [109] and the current clinical practice of harvesting chondrocytes irrespective of their original zonal location.

The effects of OP, to a certain extent, also depend on the culture model: in alginate, higher proliferation rates, with diminished sulfated GAG production, were found at $280 \mathrm{mOsm}$ [110]. Of note, the $\mathrm{pH}_{\mathrm{i}}$ is also osmolaritydependent and its contribution to sulfated GAG production remains speculative.

Finite element modeling showed that charged tissues (or synthetic matrices) always support larger loads than uncharged tissues. This load support derives from three sources: intrinsic matrix stiffness, HP, and OP [111].
Regulation of Phosphatases by Chemo- and Biomechanics

\section{Calcineurin as a Potential Target Molecule}

A precisely set balance between the activities of protein kinases and phosphoprotein phosphatases is crucial to regulating chondrogenesis and maintaining the chondrocyte phenotype. All of the major protein kinase families, including protein kinase A (PKA), PKC, mitogenactivated protein kinase (MAPK), and CaMK, as well as all major protein phosphatases (PP1, PP2A, and PP2B) play fundamental roles in molecular regulation in chondrocytes [112]. These signaling pathways eventually converge on targets that are involved in defining the chondrocyte phenotype, and they regulate cell shape, proliferation, differentiation, and gene expression (via transcriptional regulators such as Sox9, cAMP response element binding protein (CREB), and NFAT; see details below).

The $\mathrm{Ca}^{2+}$-dependent serine/threonine phosphoprotein phosphatase calcineurin $(\mathrm{Cn}$; also known as $\mathrm{PP} 2 \mathrm{~B})$ has been identified as a potential target to improve the chondrocyte phenotype. The $\mathrm{Cn}$ inhibitor FK506 (also known as Tacrolimus) increases the expression of chondrogenic markers during in vitro expansion in hypoosmotic culture medium [113]. Isolation and expansion of adult human articular chondrocytes in culture medium of physiologic osmolarity (i.e., $380 \mathrm{mOsm}$ ) improves chondrogenic marker gene expression and ECM production through NFAT5 [92]. Interestingly, FK506 within the range of 0.1 and $1000 \mathrm{ng} / \mathrm{mL}$ increased not only COL2A1 but also COL10A1 expression, while in human OA cells FK506 suppressed the osmolarity-induced COL10A1 expression [93]. Generally, similar anabolic and anti-hypertrophic effects were observed in ex vivo cartilage explant cultures and non-OA chondrocytes. Similar data were reported with alternative $\mathrm{Cn}$ inhibitors (i.e., cyclosporine A, CsA) in human cells [114] and in the murine AT805-derived chondrogenic ATDC5 cell line [115], where FK506 increased PG content in a dose-dependent manner without elevating alkaline phosphatase (ALP) activity.

The exact mechanism underlying the effects of $\mathrm{Cn}$ inhibition under different osmolarities is not yet understood, but $\mathrm{Cn}$ is known to induce FGF18, which can suppress noggin and facilitate BMP-related chondrogenesis-like effects [116]. This pathway may involve, among others, NFAT4-mediated induction of BMP2 [117]. FK506, but not CsA, induces ATDC5 differentiation [118], suggesting that FK506 promotes chondrogenic differentiation, at least partly, by $\mathrm{Cn}$ independent signaling routes. Since FK506 has been proven effective and safe as an anti-rheumatoid arthritis drug [119, 120], this approach may improve cell-based chondral repair strategies by interfering with adverse inflammatory or immune cell-mediated effects. 


\section{Cn-NFAT Signaling in Cartilage Pathologies}

$\mathrm{Cn}$ regulates the activity of NFAT family members in a specific and $\mathrm{Ca}^{2+} /$ calmodulin-dependent manner [121]. For a detailed overview of this vertebrate-specific phosphatase in chondrocyte physiology, the reader is referred elsewhere [112]. NFATs have arisen from an ancient precursor with a Rel domain, and Cn-NFAT signaling may be an essential process during vertebrate development [122].

After the original study by Glimcher's group had shown that all four NFATc $1-4$ proteins are expressed in the cartilage [123], Greenblatt and colleagues recently expanded the earlier studies of Ranger et al. and Wang et al. [123, 124] by demonstrating essential functions of NFATs (i.e., NFATc1 and NFATc2) in articular cartilage homeostasis [125]. NFATs have the potential to link many extracellular signals to the nuclear transcriptional machinery [126].

Greenblatt's cartilage-specific NFATc1 and NFATc2 double mutant mice showed accelerated cartilage degeneration and expression of OA markers, such as increased expression of genes encoding proteases involved in ECM degradation such as MMP13, ADAMTS-5, and hypertrophic chondrocyte markers, including COL10A1, and reduced expression of Sox 9 and PRG4, encoding lubricin. Intriguingly, NFATc1 protein expression is restricted to the superficial zone of articular cartilage, and its mRNA expression is reduced around cartilage lesions in human osteoarthritic patients [125]. A number of earlier in vitro studies suggest that NFAT signaling may also induce catabolic genes such as ADAMTS4 and 9 in chondrogenic cells $[127,128]$, which are findings contradictory to the protective roles observed in vivo. While NFATc3 seems less important for cartilage homeostasis, it may still be relevant in chondrogenesis [117]. Most notably, multiple pathways co-regulate the subcellular localization of the four $\mathrm{Ca}^{2+}$. dependent NFAT proteins (NFATc1-4). In contrast, osmotic stress, rather than $\mathrm{Ca}^{2+}$ signaling primarily regulates the more distantly related fifth family member NFAT5, as discussed above.

A recent study showed that lentiviral shRNA-mediated Nfatc2 knockdown in articular chondrocytes in vitro largely matches the in vivo phenotype and also upregulates proinflammatory cytokines [129]. In tracheal cartilage, Cav 3.2 T-type $\mathrm{Ca}^{2+}$ channels may be involved in Cn-NFAT-dependent modulation of Sox 9 expression [130••]. A previous study using other $\mathrm{Cn}$ inhibitors such as CsA had already suggested the participation of $\mathrm{Ca}^{2+}$ channels [131].

Pharmacological inhibition of Cn by FK506 promotes chondrogenic marker expression in dedifferentiated human adult chondrocytes, probably through upregulation of TGF $\beta 1$ [113]. NFAT activity seems tightly regulated by upstream signaling pathways: both activators $(\mathrm{Cn})$ and inhibitors (e.g., GSK-3) can link a large number of mechanical and biochemical stimuli to this protein family, but few extracellular regulators of NFAT activity in chondrocytes have been identified to date. Not surprisingly, pharmacological inhibition of GSK-3 $\beta$ signaling increases cartilage degeneration in rats [132], while FK506 in the same species protects the collagenous ECM of articular cartilage against osteoarthritic wearand-tear erosion [133]. At present, it is not clear whether these effects are due to altered NFAT activity or other pathways affected by the inhibitors of Cn (CsA or FK506) or GSK (GIN). Earlier studies suggest a link between osmolarityinduced signaling pathways such as MAPK or $\mathrm{Ca}^{2+}$ signaling and Cn-NFAT signaling, which may be integrated through NFAT5. NFAT activity and expression in chondrocytes in vitro seems also to be dependent on both Notch and Wnt5a signaling, at least in growth plate chondrocytes [134, 135], and its relevance for articular chondrocytes, especially in vivo, remains to be shown.

Overall, in vivo and in vitro data from mice and humans strongly suggest a dynamic control of NFATc2 expression in articular cartilage and a crucial role of NFAT family members in cartilage homeostasis and joint health. NFATs might be involved in distinguishing articular from growth plate chondrocytes, the origins of which are still not understood completely [136]. Novel small molecular compounds with higher specificities may make NFATs potential therapeutic targets for cartilage regenerative medicine and antiosteoarthritic treatment regimes.

\section{The Role of PKA and PP2A in Mechanical Stimulation and the Chondrocyte Phenotype}

A main function of articular cartilage is to absorb shock during joint movements. Chondrocytes are sensitive to mechanical load, one of the most physiological stimuli that trigger the activation of key signaling molecules. Although appropriate mechanical stimuli are essential for limb development [137], differentiation of MSCs [138], and cartilage regeneration during OA [139], mechanotransduction pathways in differentiating or mature chondrocytes are still incompletely understood [140•].

Although mechanosensitive ion channels, primary cilia, and the actin cytoskeleton have all been implicated as mechanosensors in chondrocytes, downstream pathways are even less well characterized. Of the major signaling pathways, integrins and focal adhesion kinases (FAKs), the ERK, and the PI 3-kinase/Akt pathways have been reported [141]. It is of note that activation of the cAMP-PKA-CREB axis following mechanical stimuli has been documented in different models [142]. PP2A also plays a regulatory role in p38 MAPK activation during cyclic strain [143]. Oscillating mechanical load promotes chondrogenesis and stimulates cartilage ECM production in chicken limb bud-derived micromass cultures, and the observed effects can be 
attributed to the activation of PKA/CREB-Sox9 signaling and concurrent inhibition of the PP2A pathway [144]. Here, we propose that increased PKA activity results in enhanced Sox9 and CREB phosphorylation and nuclear translocation; these in turn facilitate chondrogenic differentiation and ECM matrix production. Given that PP2A is a negative regulator of chondrogenesis and balances the effects of PKA by dephosphorylating many common targets, its reduced activity further enhances the chondrogenesis-promoting effects of mechanical stimulation in this model. Interestingly, previous data also indicated a direct interplay between PKA and PP2A during chondrogenesis [145] and strongly support the important role of reversible protein phosphorylation in establishing and maintaining the chondrocyte phenotype.

Serially passaged articular chondrocytes, deprived of their ECM, rapidly lose their characteristic phenotype. Signaling events that control the re-differentiation of dedifferentiated chondrocytes have only partially been analyzed. Chondrocyte re-differentiation in micromass cultures may be mediated by PKC-dependent ERK1/2 regulation, whereas chondrocyte dedifferentiation is under a separate control by $\mathrm{PKC} \alpha$ and ERK1/2 [146]. In a different study, p38 MAPK along with $\mathrm{PKC} \alpha$ activity was reported to be essential for chondrocyte re-differentiation [147]. Since cyclic hydrostatic pressure upregulates cartilage-specific gene expression during redifferentiation of dedifferentiated bovine articular chondrocytes [148], one can speculate that mechanical load- induced activation of protein kinases and/or phosphatases may be responsible, at least partially, for these effects.

Calcium Signaling Is an Essential Component in Mechanotransduction Pathways in Differentiating and Mature Chondrocytes

Intracellular $\mathrm{Ca}^{2+}$ signaling and changes in cytosolic $\mathrm{Ca}^{2+}$ concentration are closely related to cell proliferation and differentiation in chondroprogenitor cells, and $\mathrm{Ca}^{2+}$ release from intracellular stores and influx through plasma membrane ion channels are key factors controlling chondrogenesis [149]. Various chondrocyte plasma membrane ion channels appear to be regulated by mechanical stimuli, such as the big conductance $\mathrm{Ca}^{2+}$-activated $\mathrm{K}^{+}$channel (BK-like channel) [150] or the transient receptor potential vanilloid 4 (TRPV4) cation channel $\left[151 \bullet \bullet\right.$. Mechanical load-induced $\mathrm{Ca}^{2+}$ influx and subsequent alterations in $\mathrm{Ca}^{2+}$ signaling have been documented in chondrocytes upon both compressive loading and HP [152]. Furthermore, cyclic compression is known to modulate cartilage matrix synthesis and catabolism through an autocrine/paracrine purinergic pathway; compressioninduced ATP release evokes $\mathrm{Ca}^{2+}$ transients via activation of $\mathrm{P} 2 \mathrm{X}$ and $\mathrm{P} 2 \mathrm{Y}$ receptors that cause a combination of extracellular $\mathrm{Ca}^{2+}$ influx and intracellular $\mathrm{Ca}^{2+}$ release in agaroseembedded chondrocytes [101]. How exactly $\mathrm{Ca}^{2+}$ signaling is coupled to mechanosensation in chondrocytes remains an open question.
Fig. 1 The effects of electrical, magnetic, and mechanical stimulation on articular cartilage

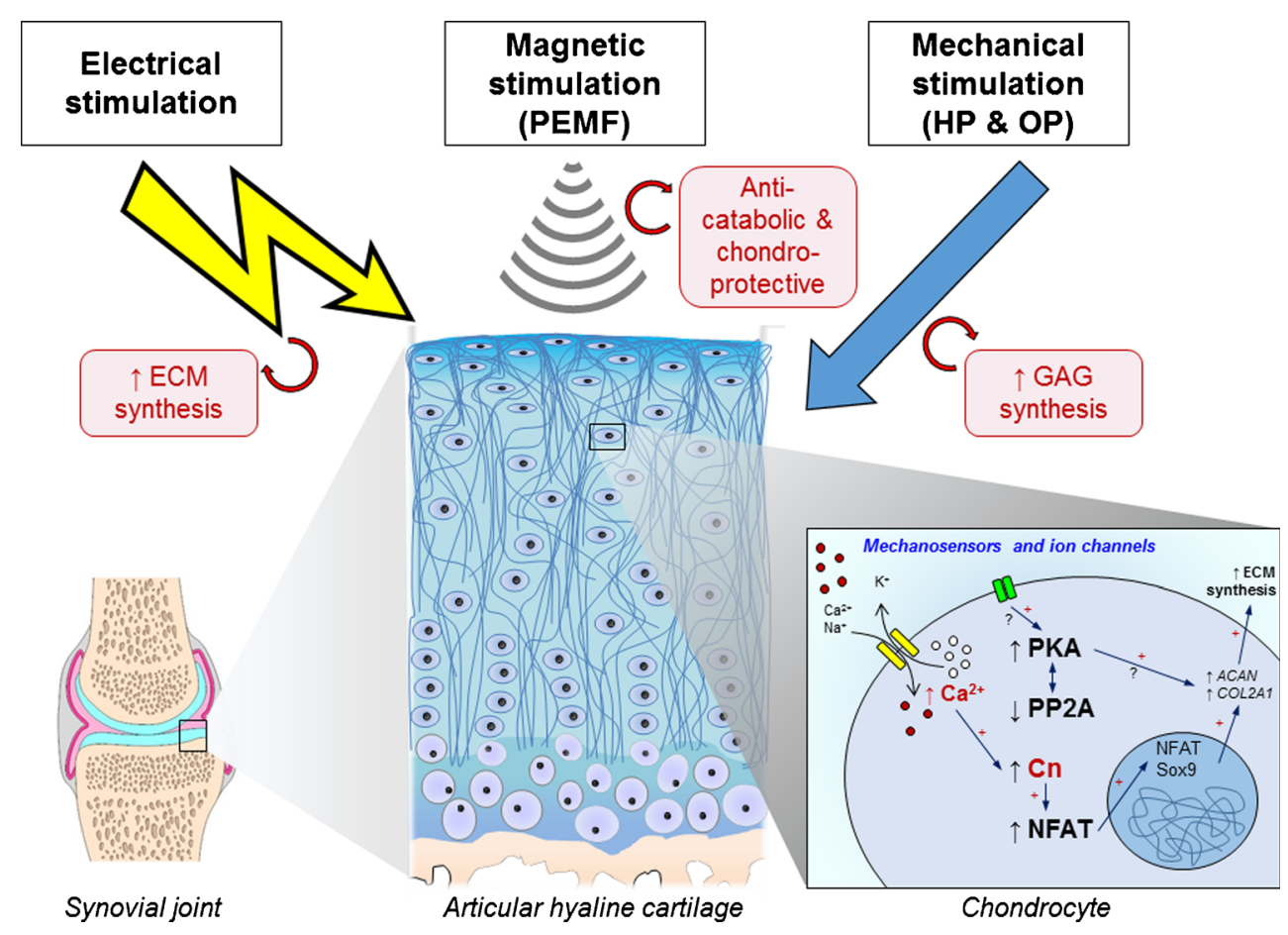


A promising candidate for a mechanosensory organelle on chondrocytes is the primary (non-motile) cilium, first identified on articular chondrocytes almost 40 years ago [153]. Tissue compression during joint loading can lead to deformation of the cilium, which in turn may trigger signaling involved in mechanotransduction pathways. Indeed, various extracellular matrix receptors including integrins, as well as osmo- and mechanosensitive ion channels including TRPV4, are known to be present on its surface [140•]. In particular, the primary cilium is necessary for compression-induced ATP release and $\mathrm{Ca}^{2+}$ signaling via $\mathrm{P} 2 \mathrm{X}$ and $\mathrm{P} 2 \mathrm{Y}$ purinergic receptors, inducing aggrecan mRNA expression and sulfated GAG secretion in a 3D chondrocyte culture system [154]. These findings suggest that the primary cilium does not act as the initial mechanosensor in that model, leaving several open questions regarding its specific role in chondrocyte mechanosensation.

\section{Conclusions}

The effects of electrical, magnetic, and mechanical stimulation on articular cartilage are summarized in Fig. 1. Data are accumulating regarding the molecular identity of the sensors and the mechanotransduction signaling apparatus in chondrocytes that convert the effects of external forces to cellular responses. Diverse stimuli have been shown to exert chondroprotective effects, but our current knowledge is still incomplete and a better understanding of the molecular identity and function of mechanotransduction pathways is of crucial importance. It is very important to emphasize that the mechanical properties of native cartilage, and thus the responsiveness of chondrocytes to external stimuli, vary widely and depend on joint location, depth in the tissue, sample orientation, species, and donor age. These differences have important implications for cellbased regenerative approaches and should be considered during data interpretation. Further research should aim at understanding which load-induced biophysical changes are most important for cartilage ECM regeneration and maintenance of the chondrocyte phenotype to benefit functional cartilage tissue engineering.

Acknowledgments C.M. is supported by the European Union through a Marie Curie Intra-European Fellowship for career development (project number 625746; acronym: CHONDRION; FP7-PEOPLE-2013-IEF). A.M. is the coordinator of the D-BOARD Consortium (EU FP7; HEAL TH.2012.2.4.5-2, project number 305815). C.M. is a member of the DBOARD. H.J. is also a member of the D-BOARD and is indebted to the START-Program of the Faculty of Medicine of the RWTH Aachen and the Aachen Interdisciplinary Center for Clinical Research (IZKF).

\section{Compliance with Ethics Guidelines}

Conflict of Interest Holger Jahr, Csaba Matta, and Ali Mobasheri declare no conflicts of interest.
Human and Animal Rights and Informed Consent This article does not contain any studies with human or animal subjects performed by any of the authors.

Open Access This article is distributed under the terms of the Creative Commons Attribution License which permits any use, distribution, and reproduction in any medium, provided the original author(s) and the source are credited.

\section{References}

Papers of particular interest, published recently, have been highlighted as:

- Of importance

•- Of major importance

1. Mow VC, Ratcliffe A, Poole AR. Cartilage and diarthrodial joints as paradigms for hierarchical materials and structures. Biomaterials. 1992;13(2):67-97.

2. Lesperance LM, Gray ML, Burstein D. Determination of fixed charge density in cartilage using nuclear magnetic resonance. J Orthop Res. 1992;10(1):1-13.

3. Mow VCYGW, Hui CF. Structure and function of articular cartilage and meniscus. Basic orthopaedic biomechanics and mechanobiology. Philadelphia (PA): Lippincott Williams \& Wilkins; 2005.

4. Mow VC, Ateshian GA, Spilker RL. Biomechanics of diarthrodial joints: a review of twenty years of progress. J Biomech Eng. 1993;115(4B):460-7.

5. Maroudas AI. Balance between swelling pressure and collagen tension in normal and degenerate cartilage. Nature. 1976;260(5554):808-9.

6. Lai WM, Mow VC, Sun DD, Ateshian GA. On the electric potentials inside a charged soft hydrated biological tissue: streaming potential versus diffusion potential. J Biomech Eng. 2000;122(4):336-46.

7. Bassett CA, Pawluk RJ. Electrical behavior of cartilage during loading. Science. 1972;178(4064):982-3.

8. Buschmann MD, Grodzinsky AJ. A molecular model of proteoglycan-associated electrostatic forces in cartilage mechanics. J Biomech Eng. 1995;117(2):179-92.

9. Chen AC, Nguyen TT, Sah RL. Streaming potentials during the confined compression creep test of normal and proteoglycandepleted cartilage. Ann Biomed Eng. 1997;25(2):269-77.

10. Mow VC, Guo XE. Mechano-electrochemical properties of articular cartilage: their inhomogeneities and anisotropies. Annu Rev Biomed Eng. 2002;4:175-209.

11. Mow VC, Wang CC, Hung CT. The extracellular matrix, interstitial fluid and ions as a mechanical signal transducer in articular cartilage. Osteoarthr Cartil. 1999;7(1):41-58.

12. Little CJ, Bawolin NK, Chen X. Mechanical properties of natural cartilage and tissue-engineered constructs. Tissue Eng B Rev. 2011;17(4):213-27.

13. Smith GD, Knutsen G, Richardson JB. A clinical review of cartilage repair techniques. J Bone Joint Surg (Br). 2005;87(4):445-9.

14. Domarad BR, Buschmann MT. Interviewing older adults: increasing the credibility of interview data. J Gerontol Nurs. 1995;21(9): $14-20$.

15. Jordan MA, Van Thiel GS, Chahal J, Nho SJ. Operative treatment of chondral defects in the hip joint: a systematic review. Curr Rev Musculoskelet Med. 2012;5(3):244-53. 
16. Zhang W, Moskowitz RW, Nuki G, Abramson S, Altman RD, Arden N, et al. OARSI recommendations for the management of hip and knee osteoarthritis, part I: critical appraisal of existing treatment guidelines and systematic review of current research evidence. Osteoarthr Cart. 2007;15(9):981-1000.

17. Heinegard D, Saxne T. The role of the cartilage matrix in osteoarthritis. Nat Rev Rheumatol. 2011;7(1):50-6.

18. Brady MA, Waldman SD, Ethier CR. The Application of multiple biophysical cues to engineer functional neo-cartilage for treatment of osteoarthritis (part I: cellular response). Tissue Eng Part B Rev. 2014. This recent paper highlights the fact that tissue engineering strategies and the development of "smart" functionalized biomaterials that enable the delivery of growth factors or integration of conjugated nanoparticles may benefit from targeting known signal transduction pathways in combination with external biophysical cues.

19. Grodzinsky AJ, Levenston ME, Jin M, Frank EH. Cartilage tissue remodeling in response to mechanical forces. Annu Rev Biomed Eng. 2000;2:691-713.

20. Bondeson J, Wainwright $\mathrm{S}$, Hughes $\mathrm{C}$, Caterson B. The regulation of the ADAMTS4 and ADAMTS5 aggrecanases in osteoarthritis: a review. Clin Exp Rheumatol. 2008;26(1):139-45.

21. Malemud CJ, Papay RS, Hering TM, Holderbaum D, Goldberg VM, Haqqi TM. Phenotypic modulation of newly synthesized proteoglycans in human cartilage and chondrocytes. Osteoarthr Cart. 1995;3(4):227-38

22. Nelson F, Billinghurst RC, Pidoux I, Reiner A, Langworthy M, McDermott M, et al. Early post-traumatic osteoarthritis-like changes in human articular cartilage following rupture of the anterior cruciate ligament. Osteoarthr Cart. 2006;14(2):114-9.

23. Williamson AK, Chen AC, Sah RL. Compressive properties and function-composition relationships of developing bovine articular cartilage. J Orthop Res. 2001;19(6):1113-21.

24. Bank RA, Soudry M, Maroudas A, Mizrahi J, TeKoppele JM. The increased swelling and instantaneous deformation of osteoarthritic cartilage is highly correlated with collagen degradation. Arthritis Rheum. 2000;43(10):2202-10.

25. Brittberg M, Lindahl A, Nilsson A, Ohlsson C, Isaksson O, Peterson L. Treatment of deep cartilage defects in the knee with autologous chondrocyte transplantation. N Engl J Med. 1994;331(14):889-95.

26. Saris DB, Vanlauwe J, Victor J, Haspl M, Bohnsack M, Fortems Y, et al. Characterized chondrocyte implantation results in better structural repair when treating symptomatic cartilage defects of the knee in a randomized controlled trial versus microfracture. Am J Sports Med. 2008;36(2):235-46.

27. Kock L, van Donkelaar CC, Ito K. Tissue engineering of functional articular cartilage: the current status. Cell Tissue Res. 2012;347(3):613-27.

28. Mansour JM, Welter JF. Multimodal evaluation of tissueengineered cartilage. J Med Biol Eng. 2013;33(1):1-16.

29. Miot S, Scandiucci de Freitas P, Wirz D, Daniels AU, Sims TJ, Hollander AP, et al. Cartilage tissue engineering by expanded goat articular chondrocytes. J Orthop Res. 2006;24(5):1078-85.

30. Waldman SD, Grynpas MD, Pilliar RM, Kandel RA. The use of specific chondrocyte populations to modulate the properties of tissue-engineered cartilage. J Orthop Res. 2003;21(1):132-8.

31. Darling EM, Athanasiou KA. Retaining zonal chondrocyte phenotype by means of novel growth environments. Tissue Eng. 2005;11(3-4):395-403.

32. Darling EM, Hu JC, Athanasiou KA. Zonal and topographical differences in articular cartilage gene expression. J Orthop Res. 2004;22(6):1182-7.

33. Khan IM, Gilbert SJ, Singhrao SK, Duance VC, Archer CW. Cartilage integration: evaluation of the reasons for failure of integration during cartilage repair. A review. Eur Cell Mater. 2008;16:26-39.

34. Gilbert SJ, Singhrao SK, Khan IM, Gonzalez LG, Thomson BM, Burdon D, et al. Enhanced tissue integration during cartilage repair in vitro can be achieved by inhibiting chondrocyte death at the wound edge. Tissue Eng A. 2009;15(7):1739-49.

35. Snyder MJ, Wilensky JA, Fortin JD. Current applications of electrotherapeutics in collagen healing. Pain Physician. 2002;5(2):172-81.

36. Zuzzi DC, Ciccone Cde C, Neves LM, Mendonca JS, Joazeiro PP, Esquisatto MA. Evaluation of the effects of electrical stimulation on cartilage repair in adult male rats. Tissue Cell. 2012;45(4):27581.

37. Balint R, Cassidy NJ, Cartmell SH. Electrical stimulation: a novel tool for tissue engineering. Tissue Eng B Rev. 2013;19(1):48-57.

38. Armstrong PF, Brighton CT, Star AM. Capacitively coupled electrical stimulation of bovine growth plate chondrocytes grown in pellet form. J Orthop Res. 1988;6(2):265-71.

39. Brighton CT, Jensen L, Pollack SR, Tolin BS, Clark CC. Proliferative and synthetic response of bovine growth plate chondrocytes to various capacitively coupled electrical fields. J Orthop Res. 1989;7(5):759-65.

40. Brighton CT, Wang W, Clark CC. The effect of electrical fields on gene and protein expression in human osteoarthritic cartilage explants. J Bone Joint Surg Am. 2008;90(4):833-48.

41. Assiotis A, Sachinis NP, Chalidis BE. Pulsed electromagnetic fields for the treatment of tibial delayed unions and nonunions. A prospective clinical study and review of the literature. J Orthop Surg Res. 2012;7:24.

42. Hannemann PF, Mommers EH, Schots JP, Brink PR, Poeze M. The effects of low-intensity pulsed ultrasound and pulsed electromagnetic fields bone growth stimulation in acute fractures: a systematic review and meta-analysis of randomized controlled trials. Arch Orthop Trauma Surg. 2014;134(8):1093-106. doi:10.1007/ s00402-014-2014-8. This recent paper is a systematic review and meta-analysis that suggests low-intensity pulsed ultrasound and pulsed electromagnetic fields can be beneficial in the treatment of acute fractures.

43. Chalidis B, Sachinis N, Assiotis A, Maccauro G. Stimulation of bone formation and fracture healing with pulsed electromagnetic fields: biologic responses and clinical implications. Int $\mathrm{J}$ Immunopathol Pharmacol. 2011;24(1 Suppl 2):17-20.

44. Jansen JH, van der Jagt OP, Punt BJ, Verhaar JA, van Leeuwen JP, Weinans $\mathrm{H}$, et al. Stimulation of osteogenic differentiation in human osteoprogenitor cells by pulsed electromagnetic fields: an in vitro study. BMC Musculoskelet Disord. 2010;11:188.

45. Dini L, Abbro L. Bioeffects of moderate-intensity static magnetic fields on cell cultures. Micron. 2005;36(3):195-217.

46. Fini M, Giavaresi G, Carpi A, Nicolini A, Setti S, Giardino R. Effects of pulsed electromagnetic fields on articular hyaline cartilage: review of experimental and clinical studies. Biomed Pharmacother. 2005;59(7):388-94.

47. Vavken P, Arrich F, Schuhfried O, Dorotka R. Effectiveness of pulsed electromagnetic field therapy in the management of osteoarthritis of the knee: a meta-analysis of randomized controlled trials. J Rehabil Med. 2009;41(6):406-11.

48. Sadoghi P, Leithner A, Dorotka R, Vavken P. Effect of pulsed electromagnetic fields on the bioactivity of human osteoarthritic chondrocytes. Orthopedics. 2013;36(3):e360-5.

49. Fioravanti A, Nerucci F, Collodel G, Markoll R, Marcolongo R. Biochemical and morphological study of human articular chondrocytes cultivated in the presence of pulsed signal therapy. Ann Rheum Dis. 2002;61(11):1032-3.

50. Vincenzi F, Targa M, Corciulo C, Gessi S, Merighi S, Setti S, et al. Pulsed electromagnetic fields increased the anti-inflammatory effect of $\mathrm{A}(2) \mathrm{A}$ and $\mathrm{A}(3)$ adenosine receptors in human T/C-28a2 
chondrocytes and hFOB 1.19 osteoblasts. PLoS One. 2013;8(5): e65561.

51. Ongaro A, Pellati A, Masieri FF, Caruso A, Setti S, Cadossi R, et al. Chondroprotective effects of pulsed electromagnetic fields on human cartilage explants. Bioelectromagnetics. 2011;32(7): $543-51$.

52. Luo Q, Li SS, He C, He H, Yang L, Deng L. Pulse electromagnetic fields effects on serum E2 levels, chondrocyte apoptosis, and matrix metalloproteinase-13 expression in ovariectomized rats. Rheumatol Int. 2009;29(8):927-35.

53. Mizuno S, Ogawa R. Using changes in hydrostatic and osmotic pressure to manipulate metabolic function in chondrocytes. Am J Physiol Cell Physiol. 2011;300(6):C1234-45.

54. Urban JP. The chondrocyte: a cell under pressure. Br J Rheumatol. 1994;33(10):901-8.

55. Holmvall K, Camper L, Johansson S, Kimura JH, LundgrenAkerlund E. Chondrocyte and chondrosarcoma cell integrins with affinity for collagen type II and their response to mechanical stress. Exp Cell Res. 1995;221(2):496-503.

56. Vunjak-Novakovic G, Goldstein S. Biomechanical principles of cartilage and bone tissue engineering. Basic orthopaedic biomechanics and mechano-biology. Lippincott Williams and Wilkins; 2005.

57. Lee C, Grad S, Wimmer M, Alini M. mechanical stimuli in articular cartilage tissue engineering. Topics in Tissue Engineering. 2006.

58. Vanderploeg EJ, Wilson CG, Levenston ME. Articular chondrocytes derived from distinct tissue zones differentially respond to in vitro oscillatory tensile loading. Osteoarthr Cart. 2008;16(10):1228-36.

59. Li Z, Yao S, Alini M, Grad S. Different response of articular chondrocyte subpopulations to surface motion. Osteoarthr Cart. 2007;15(9):1034-41.

60. Grad S, Eglin D, Alini M, Stoddart MJ. Physical stimulation of chondrogenic cells in vitro: a review. Clin Orthop Relat Res. 2011;469(10):2764-72.

61. Unadkat HV, Hulsman M, Cornelissen K, Papenburg BJ, Truckenmuller RK, Carpenter AE, et al. An algorithm-based topographical biomaterials library to instruct cell fate. Proc Natl Acad Sci U S A. 2011;108(40):16565-70.

62. Park S, Im GI. Stem cell responses to nanotopography. J Biomed Mater Res A. 2014. This review provides an overview of the effects of nanotopography on cell behavior in the context of musculoskeletal regeneration.

63. Yim EK, Sheetz MP. Force-dependent cell signaling in stem cell differentiation. Stem Cell Res Ther. 2012;3(5):41.

64. Discher DE, Janmey P, Wang YL. Tissue cells feel and respond to the stiffness of their substrate. Science. 2005;310(5751):1139-43.

65. Janmey PA, Wells RG, Assoian RK, McCulloch CA. From tissue mechanics to transcription factors. Differentiation. 2013;86(3): 112-20.

66. Cigognini D, Lomas A, Kumar P, Satyam A, English A, Azeem A, et al. Engineering in vitro microenvironments for cell based therapies and drug discovery. Drug Discov Today. 2013;18(21-22): 1099-108.

67. Orsi G, Fagnano M, De Maria C, Montemurro F, Vozzi G. A new 3D concentration gradient maker and its application in building hydrogels with a 3D stiffness gradient. J Tissue Eng Regen Med. 2014.

68. Schuh E, Hofmann S, Stok K, Notbohm H, Muller R, Rotter N. Chondrocyte redifferentiation in 3D: the effect of adhesion site density and substrate elasticity. J Biomed Mater Res A. 2012;100(1):38-47.

69. Jiang F, Horber H, Howard J, Muller DJ. Assembly of collagen into microribbons: effects of $\mathrm{pH}$ and electrolytes. J Struct Biol. 2004;148(3):268-78.
70. Little WC, Smith ML, Ebneter U, Vogel V. Assay to mechanically tune and optically probe fibrillar fibronectin conformations from fully relaxed to breakage. Matrix Biol. 2008;27(5):451-61.

71. Smith ML, Gourdon D, Little WC, Kubow KE, Eguiluz RA, Luna-Morris S, et al. Force-induced unfolding of fibronectin in the extracellular matrix of living cells. PLoS Biol. 2007;5(10): e268.

72.• Lee J, Abdeen AA, Kilian KA. Rewiring mesenchymal stem cell lineage specification by switching the biophysical microenvironment. Sci Rep. 2014;4:5188. doi:10.1038/srep05188. This important new study demonstrates that MSCs remain susceptible to the biophysical properties of the extracellular matrix - even after several weeks of culture-and can redirect lineage specification in response to changes in the microenvironment.

73. Liu C, Baek S, Kim J, Vasko E, Pyne R, Chan C. Effect of static pre-stretch induced surface anisotropy on orientation of mesenchymal stem cells. Cell Mol Bioeng. 2014;7(1):106-21.

74. Li Y, Chu JS, Kurpinski K, Li X, Bautista DM, Yang L, et al. Biophysical regulation of histone acetylation in mesenchymal stem cells. Biophys J. 2011;100(8):1902-9.

75. Wang N, Tytell JD, Ingber DE. Mechanotransduction at a distance: mechanically coupling the extracellular matrix with the nucleus. Nat Rev Mol Cell Biol. 2009;10(1):75-82.

76. Gieni RS, Hendzel MJ. Mechanotransduction from the ECM to the genome: are the pieces now in place? J Cell Biochem. 2008;104(6):1964-87.

77. Crisp M, Liu Q, Roux K, Rattner JB, Shanahan C, Burke B, et al. Coupling of the nucleus and cytoplasm: role of the LINC complex. J Cell Biol. 2006;172(1):41-53.

78. Steinmetz NJ, Bryant SJ. Chondroitin sulfate and dynamic loading alter chondrogenesis of human MSCs in PEG hydrogels. Biotechnol Bioeng. 2012;109(10):2671-82.

79. Mhanna R, Kashyap A, Palazzolo G, Vallmajo-Martin Q, Becher $\mathrm{J}$, Moller S, et al. Chondrocyte culture in three dimensional alginate sulfate hydrogels promotes proliferation while maintaining expression of chondrogenic markers. Tissue Eng A. 2014;20(910):1454-64.

80. Govey PM, Loiselle AE, Donahue HJ. Biophysical regulation of stem cell differentiation. Curr Osteoporos Rep. 2013;11(2):83-91.

81. Trappmann B, Chen CS. How cells sense extracellular matrix stiffness: a material's perspective. Curr Opin Biotechnol. 2013;24(5):948-53.

82. Breuls RG, Jiya TU, Smit TH. Scaffold stiffness influences cell behavior: opportunities for skeletal tissue engineering. Open Orthop J. 2008;2:103-9.

83. Hing WA, Sherwin AF, Poole CA. The influence of the pericellular microenvironment on the chondrocyte response to osmotic challenge. Osteoarthr Cart. 2002;10(4):297-307.

84. Likhitpanichkul M, Guo XE, Mow VC. The effect of matrix tension-compression nonlinearity and fixed negative charges on chondrocyte responses in cartilage. Mol Cell Biomech. 2005;2(4): 191-204.

85. Lai WM, Gu WY, Mow VC. On the conditional equivalence of chemical loading and mechanical loading on articular cartilage. J Biomech. 1998;31(12):1181-5.

86. Schneiderman R, Keret D, Maroudas A. Effects of mechanical and osmotic pressure on the rate of glycosaminoglycan synthesis in the human adult femoral head cartilage: an in vitro study. J Orthop Res. 1986;4(4):393-408.

87. Guilak F, Erickson GR, Ting-Beall HP. The effects of osmotic stress on the viscoelastic and physical properties of articular chondrocytes. Biophys J. 2002;82(2):720-7.

88. Cheung CY, Ko BC. NFAT5 in cellular adaptation to hypertonic stress-regulations and functional significance. J Mol Signal. 2013;8(1):5. 
89. Jeon US, Kim JA, Sheen MR, Kwon HM. How tonicity regulates genes: story of TonEBP transcriptional activator. Acta Physiol (Oxf). 2006;187(1-2):241-7.

90. Lee SD, Choi SY, Lim SW, Lamitina ST, Ho SN, Go WY, et al. TonEBP stimulates multiple cellular pathways for adaptation to hypertonic stress: organic osmolyte-dependent and -independent pathways. Am J Physiol Renal Physiol. 2011;300(3):F707-15.

91. Halterman JA, Kwon HM, Wamhoff BR. Tonicity-independent regulation of the osmosensitive transcription factor TonEBP (NFAT5). Am J Physiol Cell Physiol. 2012;302(1):C1-8.

92. van der Windt AE, Haak E, Das RH, Kops N, Welting TJ, Caron MM, et al. Physiological tonicity improves human chondrogenic marker expression through nuclear factor of activated T-cells 5 in vitro. Arthritis Res Ther. 2010;12(3):R100.

93. van der Windt AE, Haak E, Kops N, Verhaar JA, Weinans H, Jahr $\mathrm{H}$. Inhibiting calcineurin activity under physiologic tonicity elevates anabolic but suppresses catabolic chondrocyte markers. Arthritis Rheum. 2012;64(6):1929-39.

94. Koo J, Kim KI, Min BH, Lee GM. Controlling medium osmolality improves the expansion of human articular chondrocytes in serum-free media. Tissue Eng C Methods. 2010;16(5):957-63.

95. Koo J, Kim KI, Min BH, Lee GM. Differential protein expression in human articular chondrocytes expanded in serum-free media of different medium osmolalities by DIGE. J Proteome Res. 2010;9(5):2480-7.

96. Peffers MJ, Milner PI, Tew SR, Clegg PD. Regulation of SOX9 in normal and osteoarthritic equine articular chondrocytes by hyperosmotic loading. Osteoarthr Cart. 2010;18(11):1502-8.

97. Tew SR, Peffers MJ, McKay TR, Lowe ET, Khan WS, Hardingham TE, et al. Hyperosmolarity regulates SOX9 mRNA posttranscriptionally in human articular chondrocytes. Am J Physiol Cell Physiol. 2009;297(4):C898-906.

98. Tsai TT, Danielson KG, Guttapalli A, Oguz E, Albert TJ, Shapiro IM, et al. TonEBP/OREBP is a regulator of nucleus pulposus cell function and survival in the intervertebral disc. J Biol Chem. 2006;281:25416-25424.

99. Gajghate S, Hiyama A, Shah M, Sakai D, Anderson DG, Shapiro IM, et al. Osmolarity and intracellular calcium regulate aquaporin2 expression through TonEBP in nucleus pulposus cells of the intervertebral disc. J Bone Miner Res. 2009;24(6):992-1001.

100. Tsai TT, Guttapalli A, Agrawal A, Albert TJ, Shapiro IM, Risbud MV. MEK/ERK signaling controls osmoregulation of nucleus pulposus cells of the intervertebral disc by transactivation of TonEBP/OREBP. J Bone Miner Res. 2007;22(7):965-74.

101. Pingguan-Murphy B, El-Azzeh M, Bader DL, Knight MM. Cyclic compression of chondrocytes modulates a purinergic calcium signalling pathway in a strain rate- and frequency-dependent manner. J Cell Physiol. 2006;209(2):389-97.

102. Hiyama A, Gajghate S, Sakai D, Mochida J, Shapiro IM, Risbud MV. Activation of TonEBP by calcium controls \{beta 1,3 -glucuronosyltransferase-I expression, a key regulator of glycosaminoglycan synthesis in cells of the intervertebral disc. J Biol Chem. 2009;284(15):9824-34.

103. Erickson GR, Alexopoulos LG, Guilak F. Hyper-osmotic stress induces volume change and calcium transients in chondrocytes by transmembrane, phospholipid, and G-protein pathways. J Biomech. 2001;34(12):1527-35.

104. Pritchard S, Votta BJ, Kumar S, Guilak F. Interleukin-1 inhibits osmotically induced calcium signaling and volume regulation in articular chondrocytes. Osteoarthr Cart. 2008;16(12):1466-73.

105. Sanchez JC, Lopez-Zapata DF. Effects of osmotic challenges on membrane potential in human articular chondrocytes from healthy and osteoarthritic cartilage. Biorheology. 2010;47(5-6):321-31.

106. Korhonen RK, Han SK, Herzog W. Osmotic loading of articular cartilage modulates cell deformations along primary collagen fibril directions. J Biomech. 2010;43(4):783-7.
107. Finan JD, Chalut KJ, Wax A, Guilak F. Nonlinear osmotic properties of the cell nucleus. Ann Biomed Eng. 2009;37(3):477-91.

108. Szafranski JD, Grodzinsky AJ, Burger E, Gaschen V, Hung HH, Hunziker EB. Chondrocyte mechanotransduction: effects of compression on deformation of intracellular organelles and relevance to cellular biosynthesis. Osteoarthr Cart. 2004;12(12):937-46.

109. Oswald ES, Chao PH, Bulinski JC, Ateshian GA, Hung CT. Dependence of zonal chondrocyte water transport properties on osmotic environment. Cell Mol Bioeng. 2008;1(4):339-48.

110. Xu X, Urban JP, Tirlapur UK, Cui Z. Osmolarity effects on bovine articular chondrocytes during three-dimensional culture in alginate beads. Osteoarthr Cart. 2010;18(3):433-9.

111. Sun DD, Guo XE, Likhitpanichkul M, Lai WM, Mow VC. The influence of the fixed negative charges on mechanical and electrical behaviors of articular cartilage under unconfined compression. J Biomech Eng. 2004;126(1):6-16.

112. Matta C, Mobasheri A, Gergely P, Zakany R. Ser/Thrphosphoprotein phosphatases in chondrogenesis: neglected components of a two-player game. Cell Signal. 2014;26(10):2175-85.

113. van der Windt AE, Jahr H, Farrell E, Verhaar JA, Weinans H, van Osch GJ. Calcineurin inhibitors promote chondrogenic marker expression of dedifferentiated human adult chondrocytes via stimulation of endogenous TGFbeta1 production. Tissue Eng A. 2010;16(1):1-10.

114. Yoo SA, Park BH, Yoon HJ, Lee JY, Song JH, Kim HA, et al. Calcineurin modulates the catabolic and anabolic activity of chondrocytes and participates in the progression of experimental osteoarthritis. Arthritis Rheum. 2007;56(7):2299-311.

115. Nakamura Y, Takarada T, Kodama A, Hinoi E, Yoneda Y. Predominant promotion by tacrolimus of chondrogenic differentiation to proliferating chondrocytes. J Pharmacol Sci. 2009;109(3):413-23.

116. Reinhold MI, Abe M, Kapadia RM, Liao Z, Naski MC. FGF18 represses noggin expression and is induced by calcineurin. J Biol Chem. 2004;279(37):38209-19.

117. Tomita M, Reinhold MI, Molkentin JD, Naski MC. Calcineurin and NFAT4 induce chondrogenesis. J Biol Chem. 2002;277(44): 42214-8.

118. Nishigaki F, Sakuma S, Ogawa T, Miyata S, Ohkubo T, Goto T. FK506 induces chondrogenic differentiation of clonal mouse embryonic carcinoma cells, ATDC5. Eur J Pharmacol. 2002;437(3): $123-8$.

119. Obayashi K, Tomonari M, Yoshimatsu H, Fukuyama R, Ieiri I, Higuchi S, et al. Dosing time-dependency of the arthritisinhibiting effect of tacrolimus in mice. J Pharmacol Sci. 2011;116(3):264-73

120. Kang KY, Ju JH, Song YW, Yoo DH, Kim HY, Park SH Tacrolimus treatment increases bone formation in patients with rheumatoid arthritis. Rheumatol Int. 2013;33(8):2159-63.

121. Crabtree GR. Calcium, calcineurin, and the control of transcription. J Biol Chem. 2001;276(4):2313-6.

122. Wu H, Peisley A, Graef IA, Crabtree GR. NFAT signaling and the invention of vertebrates. Trends Cell Biol. 2007;17(6):251-60.

123. Ranger AM, Gerstenfeld LC, Wang J, Kon T, Bae H, Gravallese EM, et al. The nuclear factor of activated T cells (NFAT) transcription factor NFATp (NFATc2) is a repressor of chondrogenesis. $\mathrm{J}$ Exp Med. 2000;191(1):9-22.

124. Wang J, Gardner BM, Lu Q, Rodova M, Woodbury BG, Yost JG, et al. Transcription factor Nfat1 deficiency causes osteoarthritis through dysfunction of adult articular chondrocytes. J Pathol. 2009;219(2):163-72.

125. Greenblatt MB, Ritter SY, Wright J, Tsang K, Hu D, Glimcher LH, et al. NFATc1 and NFATc2 repress spontaneous osteoarthritis. Proc Natl Acad Sci U S A. 2013;110(49):19914-9.

126. Sitara D, Aliprantis AO. Transcriptional regulation of bone and joint remodeling by NFAT. Immunol Rev. 2010;233(1):286-300. 
127. Yaykasli KO, Oohashi T, Hirohata S, Hatipoglu OF, Inagawa K, Demircan K, et al. ADAMTS9 activation by interleukin 1 beta via NFATc1 in OUMS-27 chondrosarcoma cells and in human chondrocytes. Mol Cell Biochem. 2009;323(1-2):69-79.

128. Thirunavukkarasu K, Pei Y, Moore TL, Wang H, Yu XP, Geiser AG, et al. Regulation of the human ADAMTS-4 promoter by transcription factors and cytokines. Biochem Biophys Res Commun. 2006;345(1):197-204.

129. Rodova M, Lu Q, Li Y, Woodbury BG, Crist JD, Gardner BM, et al. Nfat1 regulates adult articular chondrocyte function through its age-dependent expression mediated by epigenetic histone methylation. J Bone Miner Res. 2011;26(8):1974-86.

130.• Lin SS, Tzeng BH, Lee KR, Smith RJ, Campbell KP, Chen CC. Cav3.2 T-type calcium channel is required for the NFATdependent Sox9 expression in tracheal cartilage. Proc Natl Acad Sci U S A. 2014;111(19):E1990-8. This recent study links ion channel function to the chondrocyte phenotype by demonstrating that calcium influx via the Cav3.2 T-type calcium channel regulates Sox9 expression through the calcineurin/NFAT signaling pathway during chondrogenesis in tracheal cartilage.

131. Matta C, Fodor J, Szijgyarto Z, Juhasz T, Gergely P, Csernoch L, et al. Cytosolic free $\mathrm{Ca} 2+$ concentration exhibits a characteristic temporal pattern during in vitro cartilage differentiation: a possible regulatory role of calcineurin in Ca-signalling of chondrogenic cells. Cell Calcium. 2008;44(3):310-23. doi:10.1016/j.ceca. 2007.12.010.

132. Miclea RL, Siebelt M, Finos L, Goeman JJ, Lowik CW, Oostdijk $\mathrm{W}$, et al. Inhibition of Gsk3beta in cartilage induces osteoarthritic features through activation of the canonical Wnt signaling pathway. Osteoarthr Cart. 2011;19(11):1363-72.

133. Siebelt M, van der Windt AE, Groen HC, Sandker M, Waarsing $\mathrm{JH}$, Muller C, et al. FK506 protects against articular cartilage collagenous extra-cellular matrix degradation. Osteoarthr Cart. 2014;22(4):591-600.

134. Zanotti S, Canalis E. Notch suppresses nuclear factor of activated $\mathrm{T}$ cells (NFAT) transactivation and Nfatc 1 expression in chondrocytes. Endocrinology. 2013;154(2):762-72.

135. Bradley EW, Drissi MH. WNT5A regulates chondrocyte differentiation through differential use of the CaN/NFAT and IKK/NFkappaB pathways. Mol Endocrinol. 2010;24(8):1581-93.

136. Pitsillides AA, Beier F. Cartilage biology in osteoarthritis-lessons from developmental biology. Nat Rev Rheumatol. 2011;7(11):654-63.

137. Roddy KA, Prendergast PJ, Murphy P. Mechanical influences on morphogenesis of the knee joint revealed through morphological, molecular and computational analysis of immobilised embryos. PLoS One. 2011;6(2):e17526.

138. SarrafCE, Otto WR, Eastwood M. In vitro mesenchymal stem cell differentiation after mechanical stimulation. Cell Prolif. 2011;44(1):99-108.

139. Sun HB. Mechanical loading, cartilage degradation, and arthritis. Ann N Y Acad Sci. 2010;1211:37-50.

140. O'Conor CJ, Case N, Guilak F. Mechanical regulation of chondrogenesis. Stem Cell Res Ther. 2013;4(4):61. This recent review article summarizes some of the latest findings on mechanically stimulated chondrogenesis, highlighting the effects of mechanical stimulation on matrix maintenance and terminal differentiation, as well as the use of multifactorial bioreactors.

141. Muhammad H, Rais Y, Miosge N, Ornan EM. The primary cilium as a dual sensor of mechanochemical signals in chondrocytes. Cell Mol Life Sci. 2012;69(13):2101-7.

142. Wang Y, Maciejewski BS, Lee N, Silbert O, McKnight NL, Frangos JA, et al. Strain-induced fetal type II epithelial cell differentiation is mediated via cAMP-PKA-dependent signaling pathway. Am J Physiol Lung Cell Mol Physiol. 2006;291(4):L820-7.

143. Lee T, Kim SJ, Sumpio BE. Role of PP2A in the regulation of p38 MAPK activation in bovine aortic endothelial cells exposed to cyclic strain. J Cell Physiol. 2003;194(3):349-55.

144. Juhász T, Matta C, Somogyi C, Katona É, Takács R, Soha RF, et al. Mechanical loading stimulates chondrogenesis via the PKA/ CREB-Sox9 and PP2A pathways in chicken micromass cultures. Cell Signal. 2014;26(3):468-82. doi:10.1016/j.cellsig.2013.12. 001

145. Zakany R, Szucs K, Bako E, Felszeghy S, Czifra G, Biro T, et al. Protein phosphatase $2 \mathrm{~A}$ is involved in the regulation of protein kinase A signaling pathway during in vitro chondrogenesis. Exp Cell Res. 2002;275(1):1-8.

146. Yoon YM, Kim SJ, Oh CD, Ju JW, Song WK, Yoo YJ, et al. Maintenance of differentiated phenotype of articular chondrocytes by protein kinase $\mathrm{C}$ and extracellular signal-regulated protein kinase. J Biol Chem. 2002;277(10):8412-20.

147. Lee YA, Kang SS, Baek SH, Jung JC, Jin EJ, Tak EN, et al. Redifferentiation of dedifferentiated chondrocytes on chitosan membranes and involvement of PKCalpha and P38 MAP kinase. Mol Cells. 2007;24(1):9-15.

148. Kawanishi M, Oura A, Furukawa K, Fukubayashi T, Nakamura K, Tateishi $\mathrm{T}$, et al. Redifferentiation of dedifferentiated bovine articular chondrocytes enhanced by cyclic hydrostatic pressure under a gas-controlled system. Tissue Eng. 2007;13(5):957-64.

149. Matta C, Zakany R. Calcium signalling in chondrogenesis: implications for cartilage repair. Front Biosci (Schol Ed). 2013;5:30524.

150. Mobasheri A, Lewis R, Maxwell JE, Hill C, Womack M, BarrettJolley R. Characterization of a stretch-activated potassium channel in chondrocytes. J Cell Physiol. 2010;223(2):511-8.

150.• O'Conor CJ, Leddy HA, Benefield HC, Liedtke WB, Guilak F. TRPV4-mediated mechanotransduction regulates the metabolic response of chondrocytes to dynamic loading. Proc Natl Acad Sci U S A. 2014;111(4):1316-21. In this paper, the authors demonstrate that TRPV4, a calcium-permeable, nonselective cation channel, is directly involved in regulating metabolic responses of chondrocytes to dynamic load.

152. Roberts SR, Knight MM, Lee DA, Bader DL. Mechanical compression influences intracellular $\mathrm{Ca} 2+$ signaling in chondrocytes seeded in agarose constructs. J Appl Physiol (1985). 2001;90(4): 1385-91.

153. Wilsman NJ. Cilia of adult canine articular chondrocytes. J Ultrastruct Res. 1978;64(3):270-81.

154. Wann AK, Zuo N, Haycraft CJ, Jensen CG, Poole CA, McGlashan SR, et al. Primary cilia mediate mechanotransduction through control of ATP-induced $\mathrm{Ca} 2+$ signaling in compressed chondrocytes. Faseb J. 2012;26(4):1663-71. 